\title{
Acteoside as a potential therapeutic option for primary hepatocellular carcinoma: a preclinical study
}

\author{
Di Ma ${ }^{1+}$, Juan Wang ${ }^{2+}$, Lu Liu $^{2}$, Meiqi Chen ${ }^{2}$ and Zhiyong Wang ${ }^{2 *}$
}

\begin{abstract}
Background: Hepatocellular carcinoma (HCC) is a common malignant tumor with characteristics of poor prognosis, high morbidity and mortality worldwide. In particular, only a few systemic treatment options are available for advanced HCC patients, and include sorafenib and the recently described atezolizumab plus bevacizumab regimen as possible first-line treatments. We here propose acteoside, a phenylethanoid glycoside widely distributed in many medicinal plants as a potential candidate against advanced HCC.
\end{abstract}

Methods: Cell proliferation, colony formation and migration were analyzed in the three human HCC cell lines BEL7404, HLF and JHH-7. Angiogenesis assay was performed using HUVESs. The BEL7404 or JHH-7 xenograft nude mice model was established to analyze the possible antitumor effects of acteoside. qRT-PCR and western blotting were used to reveal the potential antitumor mechanisms of acteoside.

Results: Acteoside inhibited cell proliferation, colony formation and migration in all the three human HCC cell lines BEL7404, HLF and JHH-7. The prohibition of angiogenesis by acteoside was revealed by the inhibition of tube formation and cell migration of HUVECs. The combination of acteoside and sorafenib produced stronger inhibition of cell colony formation and migration of the HCC cells as well as of angiogenesis of HUVECs. The in vivo antitumor efficacy of acteoside was further demonstrated in BEL7404 or JHH-7 xenograft nude mice model, with an enhancement when combined with sorafenib in inhibiting the growth of $\mathrm{JHH}-7$ xenograft. Further treatment of $\mathrm{JHH}-7$ cells with acteoside revealed an increase in the level of tumor suppressor protein p53 as well as a decrease of kallikrein-related peptidase (KLK1, 2, 4, 9 and 10) gene level with no significant changes of the rest of KLK1-15 genes.

Conclusions: Acteoside exerts an antitumor effect possibly through its up-regulation of p53 levels as well as inhibition of KLK expression and angiogenesis. Acteoside could be useful as an adjunct in the treatment of advanced HCC in the clinic.

Keywords: Acteoside, Hepatocellular carcinoma, Sorafenib, Xenograft, p53, Kallikrein

\footnotetext{
* Correspondence: wangzhiyong108@126.com

${ }^{\dagger}$ Di Ma and Juan Wang contributed equally to this work.

${ }^{2}$ China State Key Laboratory of New Drug \& Pharmaceutical Process, Center

for Pharmacological Evaluation and Research, Shanghai Institute of

Pharmaceutical Industry, 1111 Rd. Zhongshanbeiyi, Hongkou, Shanghai

200437, China

Full list of author information is available at the end of the article
}

C C The Author(s). 2020 Open Access This article is licensed under a Creative Commons Attribution 4.0 International License, which permits use, sharing, adaptation, distribution and reproduction in any medium or format, as long as you give appropriate credit to the original author(s) and the source, provide a link to the Creative Commons licence, and indicate if changes were made. The images or other third party material in this article are included in the article's Creative Commons licence, unless indicated otherwise in a credit line to the material. If material is not included in the article's Creative Commons licence and your intended use is not permitted by statutory regulation or exceeds the permitted use, you will need to obtain permission directly from the copyright holder. To view a copy of this licence, visit http://creativecommons.org/licenses/by/4.0/ The Creative Commons Public Domain Dedication waiver (http://creativecommons.org/publicdomain/zero/1.0/) applies to the data made available in this article, unless otherwise stated in a credit line to the data. 


\section{Background}

Hepatocellular carcinoma (HCC) is a common malignant tumor with characteristics of poor prognosis and high morbidity and mortality worldwide [1, 2]. Various factors have been identified to contribute to the occurrence and progression of $\mathrm{HCC}$, including the infection by hepatitis $\mathrm{B}$ or $\mathrm{C}$ virus, the inactivation of tumor suppressor genes such as p53, the abnormal activation of oncogenes such as K-ras and some signaling molecules such as PI3K, ERK/MAPK and Wnt/ $\beta$-catenin as well as the evasion of the host immune system [3, 4]. For the management of $\mathrm{HCC}$, resection, liver transplantation and radiofrequency ablation are options for early-stage HCC patients, yet with high rates of recurrence and metastasis $[3,5,6]$. In addition, only a few systemic treatment options are available for advanced HCC patients, and include sorafenib and the recently described atezolizumab plus bevacizumab regimen as possible first-line treatments [7]. In this context, it is of importance and interest to either develop new agents targeting multiple molecular targets or set up a new strategy such as application of combined therapy in the treatment of advanced HCC.

Acteoside is a phenylethanoid glycoside widely distributed in many medicinal plants, including Ligustrum purpurascens [8], Rehmannia glutinosa [9] and Ligstrum purpurascens [10]. Mounting evidence has shown that acteoside can exert various biological activities, including its antitumor activity. For example, acteoside showed strong antiproliferative effects on prostatic cancer cells [11]. Intraperitoneal delivery of acteoside suppressed tumor growth in a melanoma mouse model possibly through inhibiting protein kinase C [12]. In addition, acteoside potentiated the sensitization of colorectal cancer cells to 5Fluorouracil via targeting PI3K/Akt signaling [13]. Our previous data have also shown an inhibition of melanogenesis by acteoside in B16 melanoma cells [14]. Despite that, little information is available regarding the possible efficacy of acteoside in the treatment of $\mathrm{HCC}$ and the potential underlying mechanisms.

In the present study, we have shown that acteoside inhibits cell proliferation, colony formation and migration in all the three human HCC cell lines BEL7404, HLF and JHH7. The angiogenesis is also inhibited following treatment with acteoside, as shown by the inhibition of tube formation and cell migration of HUVECs. The in vivo antitumor efficacy of acteoside is further demonstrated in BEL7404 or JHH-7 xenograft nude mice model, with an enhancement when combined with sorafenib in inhibiting the growth of JHH-7 xenograft. The antitumor effects of acteoside could be ascribed to its up-regulation of p53 as well as suppression of KLKs and angiogenesis.

\section{Methods}

\section{Cell culture}

The human hepatocellular carcinoma (HCC) cell lines BEL7404, HLF and JHH7 were obtained from the American Type Culture Collection and were routinely cultured in DMEM medium containing 10\% fetal bovine serum supplemented with 100 units/ml penicillin $\mathrm{G}$ and $100 \mu \mathrm{g} / \mathrm{ml}$ streptomycin in a humidified incubator at $37^{\circ} \mathrm{C}$ with $5 \%$ carbon dioxide. Human umbilical vein endothelial cells (HUVECs) were isolated from the human umbilical cord veins (provided by ScienCell Research Laboratories, San Diego, USA) and maintained in an endothelial cell medium as described previously [15].

\section{Reagents}

Acteoside (A01) was purchased from Jiangsu Yongjian Medicine Technology Co., Ltd. (Taizhou, China; Lot No. 100581; Purity $\geq 99 \%$ by HPLC). Sorafenib was obtained from Selleck Chemicals (Houston, USA). We dissolved acteoside in $0.9 \%$ saline. The stock solution of sorafenib was prepared in dimethyl sulfoxide (DMSO; $10 \mathrm{mM}$ ), aliquotted and stored at $-20^{\circ} \mathrm{C}$.

\section{Animals}

Male BALB/c (Nu/Nu) mice (18-20 g, 6-8 weeks at the time of receipt) were used in the study (Shanghai Slac Laboratory Animal Co. Ltd., Shanghai, China). Animals were housed in individually ventilated polysulfone cages in a temperature- and light-controlled room (12 h light$12 \mathrm{~h}$ dark cycle, lights on at 7:00 a.m.) with free access to food and water. All experimental protocols were approved by the Institutional Animal Care and Use Committee and performed in accordance with the guidelines of the International Association for the Study of Pain concerning the use of laboratory animals.

\section{Cell proliferation assay}

The anti-proliferative activity was performed using the MTT assay. Briefly, cells were plated at a density of 4$5 \times 10^{3}$ cells per well in 96-well plates. After attached overnight, cells were treated with a series of concentrations of acteoside. Following the drug treatments at the indicated time point, cells were incubated with 3-(4,5Dimethylthiazol-2-yl)-2,5-diphenyltetrazolium bromide (MTT; Roche Diagnostic Corporation, Indianapolis, IN, USA. Final concentration: $5 \mu \mathrm{g} / \mathrm{ml}$ ) for $3-4 \mathrm{~h}$ at $37^{\circ} \mathrm{C}$. The formazan product was dissolved in DMSO for quantitation at a wavelength of $570 \mathrm{~nm}$.

\section{Colony formation assay}

Cells were seeded in 24-well plates at a density of 200 cells per well and allowed to attach to the bottom of the well overnight. Cells were then treated with indicated drugs at the given concentration. The culture medium 
was replaced every 3 days until colonies were visible at day 12 post-culturing. For colonies counting, the cells were fixed with $4 \%$ paraformaldehyde and stained with $0.1 \%$ crystal violet. Colonies $>10$ cells were counted under a light microscope $(\times 100$ magnification; Olympus, Tokyo, Japan).

\section{Wound healing assay}

The cells were seeded in 6 -well plates $\left(1 \times 10^{5}\right.$ cells per well) and cultured to $90 \%$ confluency. The cell layer was scratched with a sterile $200 \mu \mathrm{l}$ pipette tip to produce a wound gap. Cell migration into the wounded area was visualized at indicated time points $(0,10$ and $24 \mathrm{~h})$ under an inverted light microscope at a magnification of $\times 100$. Each experiment was performed in triplicate.

\section{Tube formation assay}

The HUVECs were cultured as previously described [15]. In brief, the 96-well plates were coated with Matrigel (BD Biosciences, Franklin Lakes, USA) according to the manufacturer's instructions and then returned to the incubator to polymerize for $30-40 \mathrm{~min}$. The HUVECs were then seeded at a density of $2 \times 10^{5}$ cells $/ \mathrm{mL}$ and treated with various given drugs for $8 \mathrm{~h}$. Tube formation was photographed with an inverted microscope at the indicated time points and analyzed using an ImageJ software.

\section{Western blotting analysis}

Total cell lysates were prepared with radioimmunoprecipitation assay buffer (RIPA) (50 mM Tris$\mathrm{HCl}$ at $\mathrm{pH} 8.0,150 \mathrm{mM} \mathrm{NaCl}, 1 \% \mathrm{NP} 40,1 \%$ sodium deoxycholate, $0.1 \%$ SDS, $10 \mu \mathrm{g} / \mathrm{ml}$ leupeptin, $10 \mu \mathrm{g} / \mathrm{ml}$ aprotinin and $2 \mathrm{mM}$ PMSF). Protein samples with equal amounts $(20 \mu \mathrm{g} / \mathrm{lane})$ were separated on SDS-PAGE gel and transferred to PVDF membranes (Bio-Rad, Hercules, CA). The membranes were incubated overnight with p53 antibody (Cell Signaling Technology, Boston, MA). For loading controls, the membranes were rinsed with a stripping buffer and reprobed with the $\beta$-actin antibody (Santa Cruz Biotechnology, Santa Cruz, CA). Proteins were detected using an ECL detection system (Perkin Elmer Life Sciences, Boston, USA).

\section{qRT-PCR}

Total RNA was extracted from cell lines using the Trizol reagent (Invitrogen, USA) and underwent a reverse transcription-polymerase chain reaction (RT-PCR) to synthesize cDNA using a commercially available kit. The real-time qRT-PCR using 2xSYBR green qPCR Supermix was conducted on the Stratagene Mx3000P PRC machine (Agilent Technologies, USA). The primer sequences were shown below: sense 5'-CACCATGTGG TTCCTGGTTC-3' and anti-sense 5' - CAAACAAGTT
GTGGCGACCC-3' for KLK1; sense 5' -GTGTACAGTC ATGGATGGGC-3' and anti-sense 5'-CCCAGAATCA CCCCCACAAG-3' for KLK2; sense 5' - CCACACCC GCTCTACGATATGA-3' and anti-sense 5'-CCCAGA ATCACCCGAGCAG-3' for KLK3; sense 5'-CGCACA CTGTTTCCAGAACTC-3' and anti-sense 5' - GTTG CAGGAGTCCTTCTGGT-3' for KLK4; sense 5' -CCTG CACCCACATCTTTCTCT-3' and anti-sense $5^{\prime}$ GGTAAGCATCCTCGCACCTT-3' for KLK5; sense 5' CTCTCTCCTGGGGACACAGA-3' and anti-sense 5'TCCGCCATGCACCAACTTAT-3' for KLK6; sense 5' TTTTGGAGCCCAGCTGTGTG-3' and anti-sense $5^{\prime}$ GTCACCATTGCAGGCGTTTT-3' for KLK7; sense 5' CTGGGCAGGACACTCCAG-3' and anti-sense ${ }^{\prime}{ }^{\prime}$ ACACCGCCACAGAGTAGTTG-3' for KLK8; sense 5' GTAGGGGGTTCTCGTAGGGT-3' and anti-sense 5' $^{\prime}$ CGGTGACGTCATAGAGACGG-3' for KLK9; sense 5'-CAGGAGTGCCAGCCTCAC-3' and anti-sense 5' CTGGGGAGGAAGAGGATGGA-3' for KLK10; sense 5'-CCCACCCCTTGGATTCTGTCT-3' and anti-sense 5'-GTGAACTATGTAGCGGGGCT-3' for KLK11; sense 5' -TGTTCTTGGTGAGTTCTCCCG-3' and antisense $\quad 5^{\prime}$-GGATCCAGTCCACATACTTGC-3' for KLK12; sense 5'-CCTGAACCACGACCATGACA-3' and anti-sense 5'-GCAGGGTTTGGATGTAGCCT-3' for KLK13; sense $5^{\prime}$-CCCAACTACAACTCCCGGAC-3' and anti-sense 5'-CCTGAAGCAACTGCTCGTGA-3' for KLK14; sense 5'-AGTTGCTGGAAGGTGACGAG$3^{\prime}$ and anti-sense $5^{\prime}$-TGGCTAACATCTGGGCCTTG3' for KLK15; sense 5'-GACAGTCAGCCGCATCTT CT-3' and anti-sense 5' - GCGCCCAATACGACCAAA TC-3' for GAPDH. The cycle threshold (Ct) values of each KLK gene were normalized to that of GAPDH and analyzed with the MxPro software.

\section{In vivo antitumor activity of A01 alone or in combination with sorafenib}

The BEL7404 cell suspensions were prepared $\left(3 \times 10^{6}\right.$ cells) and injected subcutaneously into the right flank of athymic nude mice. Ten days after the inoculation, tumor-bearing mice (body weight(g):22-26; mean \pm SEM:23.8 \pm 0.14 ) were screened and selected for randomization into 7 treatment groups in accordance with tumor volume $\left(70-120 \mathrm{~mm}^{3}\right)$. A total of 38 mice were assigned to different treatment groups $(n=5$ per group except for the model group $(n=8))$. Animals were then treated via oral gavage with acteoside (A01; 12.5, 25 and $50 \mathrm{mg} / \mathrm{kg})$, sorafenib alone $(50 \mathrm{mg} / \mathrm{kg}$ ) or in combination with A01 $(50 \mathrm{mg} / \mathrm{kg})$ once daily for 14 days. Moreover, a dose of $20 \mathrm{mg} / \mathrm{kg}$ A01 was also delivered intravenously. Doses were selected based on previous studies and our preliminary data [15]. The tumor growth was monitored every 3 or 4 days using an electronic caliper, with the volume calculated as $0.5 x$ lengthxwidth ${ }^{2}$ 

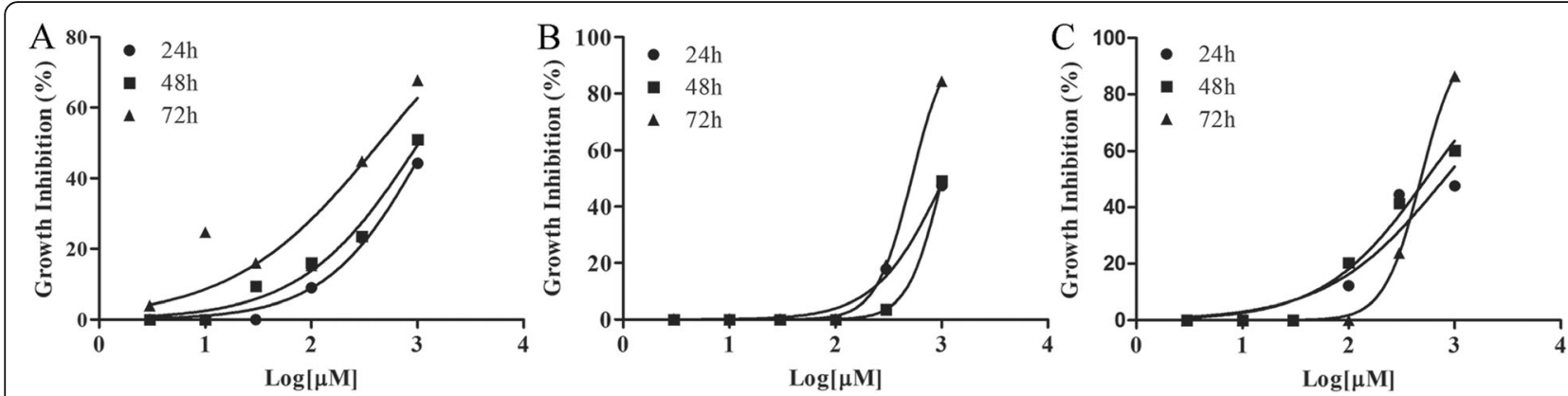

Fig. 1 Acteoside inhibits cell proliferation in HCC cells. The three human HCC cell lines BEL7404 (a), HLF (b) and JHH (c) were treated with different doses of acteoside $(3,10,30,100,300$ and $1000 \mu \mathrm{M})$ following an overnight attachment in 96-well plates. Cell proliferation was detected with MTT at $24 \mathrm{~h}, 48 \mathrm{~h}$ and $72 \mathrm{~h}$ post-treatment. Each treatment was performed in triplicate. The dose-response curve was fitted with nonlinear regression

$\left(\mathrm{mm}^{3}\right)$. In addition, a parallel experiment using JHH-7 inoculation was included. Seven days after the inoculation, tumor-bearing mice (body weight(g):20-26; mean \pm SEM:24.0 \pm 0.20 ) were screened and selected for randomization into treatment groups in accordance with tumor volume $\left(80-130 \mathrm{~mm}^{3}\right)$. A total of 23 mice were assigned to 4 treatment groups $(n=5$ per group except for the model group $(n=8)$ ). Animals then received A01 $(20 \mathrm{mg} / \mathrm{kg}$, iv), sorafenib alone $(50 \mathrm{mg} / \mathrm{kg}$, ig) or combined with A01 (20 mg/kg, iv) once daily for 14 consecutive days. All mice were anesthetized with chloral hydrate $(350 \mathrm{mg} / \mathrm{kg})$ and sacrificed by neck dislocation at the end of the observation period. And tumor mass was removed and pictured with a digital camera.

\section{Statistical analysis}

All data are expressed as mean \pm standard deviation (SD). Unless otherwise stated, statistical analyses were

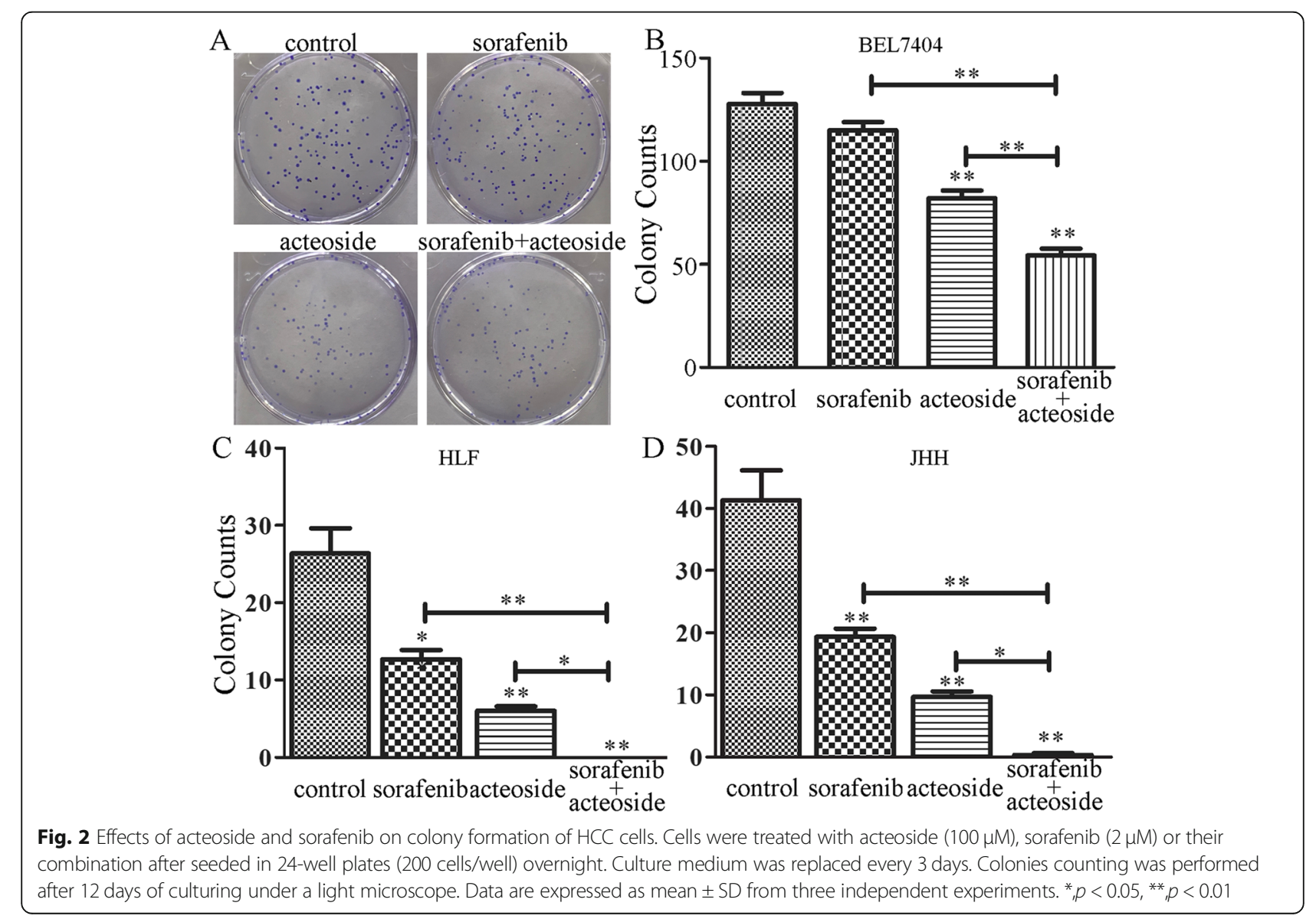




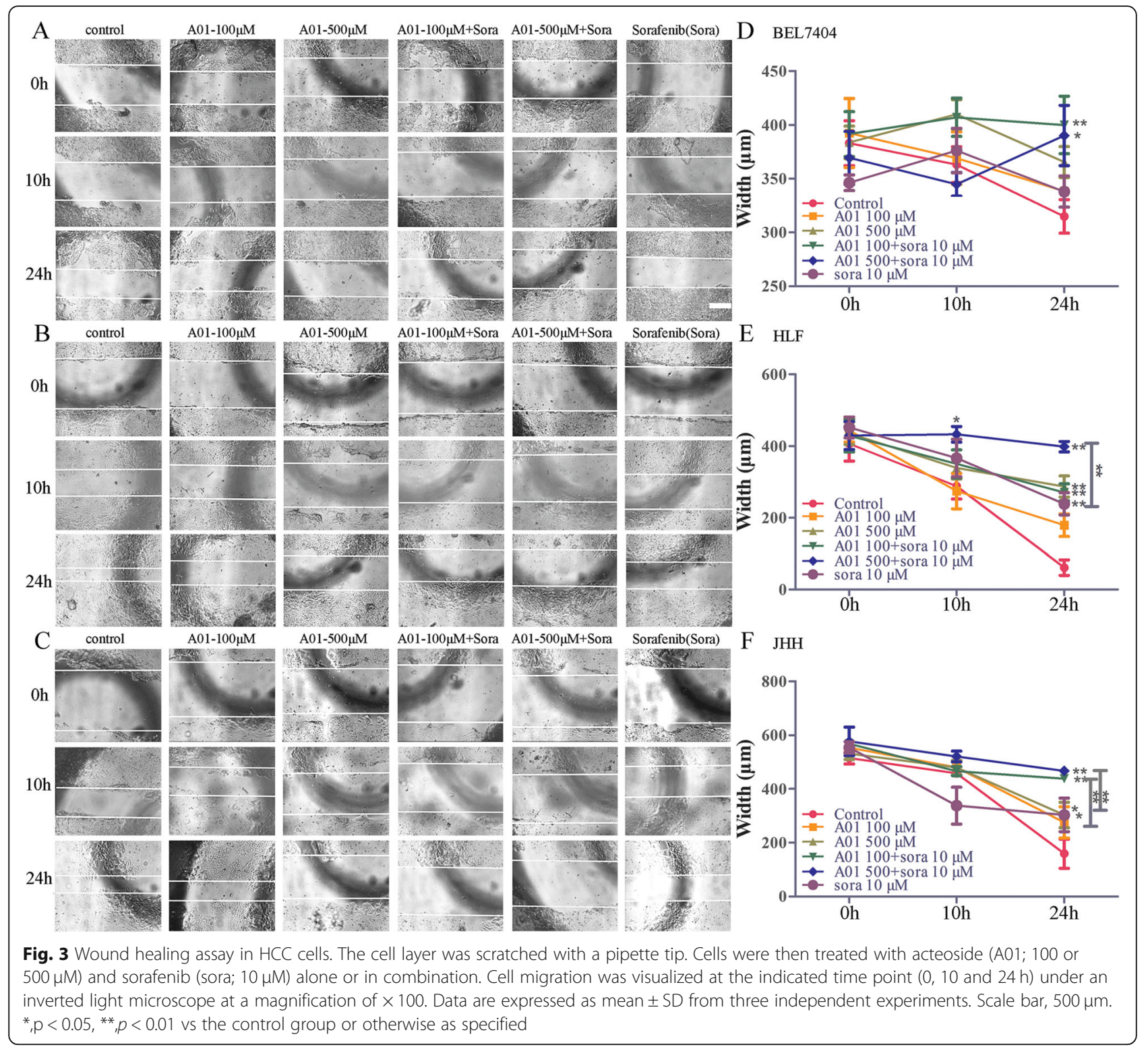

performed using analysis of variance (ANOVA) followed by a post-hoc Tukey test. Tumor volume values are shown as mean \pm standard error of mean (SEM). Twoway ANOVA followed by Tukey tests were used to analyze tumor volume data. The GraphPad Prism software was used for statistical analyses. A value of $p<0.05$ was considered statistically significant.

\section{Results}

\section{Effects of A01 on the proliferation and colony formation of HCCs in vitro}

The three HCC cell lines (BEL7404, HLF and JHH7) were used for the cell proliferation assay. As shown in Fig. 1, the MTT assay revealed that A01 inhibited the proliferation of all the three HCC cells. To further ask whether the antiproliferative activity of A01 was due to its capability of inhibiting cell clonogenicity, the colony formation assay was performed. A01 at $100 \mu \mathrm{M}$ showed a strong inhibition of colony formation in BEL7404 cells (Fig. $2 \mathrm{a}$ and b). When combined with sorafenib $(2 \mu \mathrm{M})$, the inhibition potency was stronger than that of A01 or sorafenib alone. Similar results were also seen in the other two HCC cells, HLF and JHH-7 (Fig. 2c and d).

\section{Effects of A01 alone or in combination with sorafenib on cell migration of HCCs in vitro}

We next evaluated cell migration by using the scratch wound assay. As shown in Fig. 3, the combination of A01 $(100$ or $500 \mu \mathrm{M})$ and sorafenib $(10 \mu \mathrm{M})$ significantly prevented wound healing in all the three HCC cells, when compared with the control group. For BEL7404 cells, both A01 $(100$ or $500 \mu \mathrm{M})$ and sorafenib $(10 \mu \mathrm{M})$ 


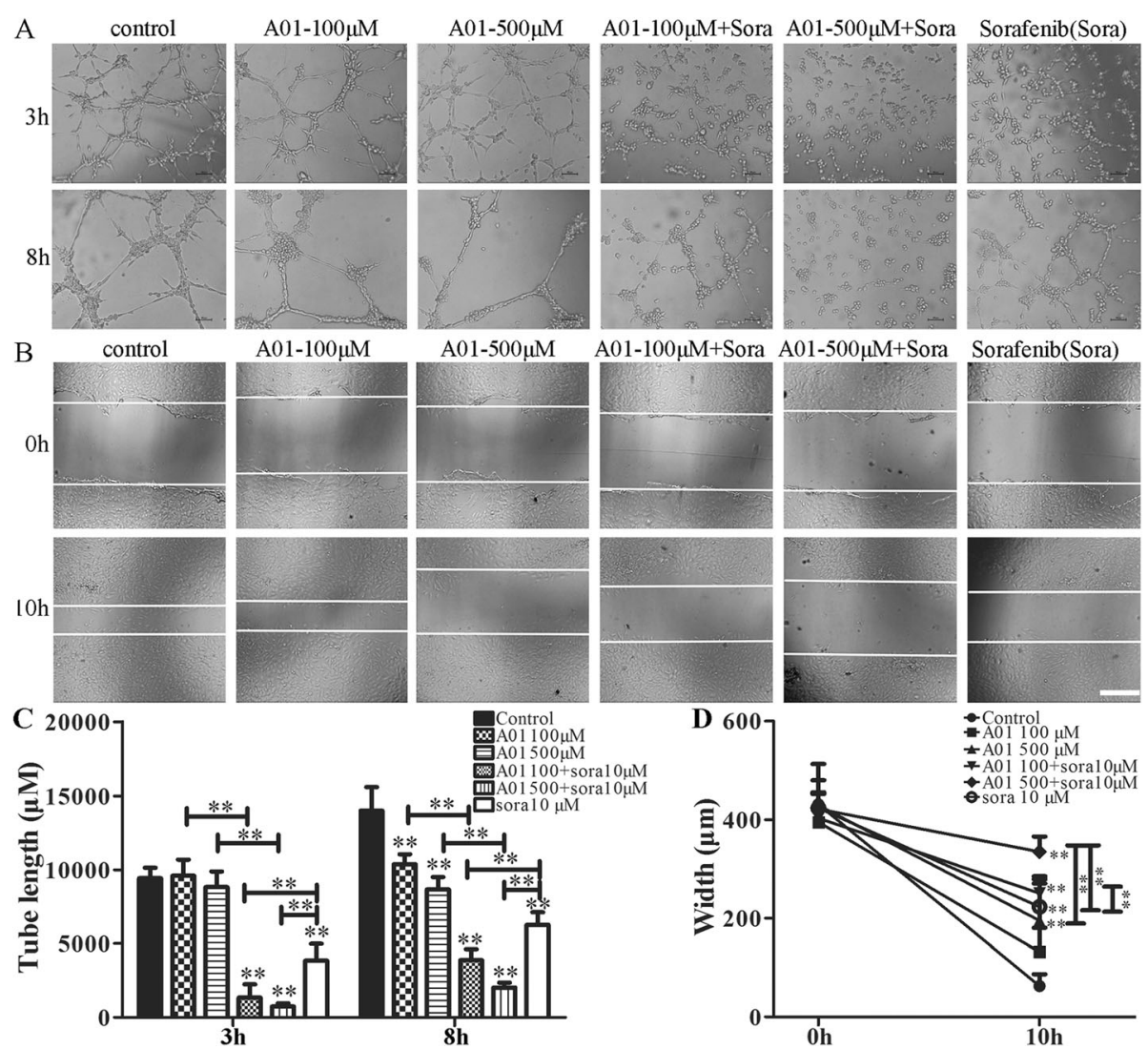

Fig. 4 Effects of acteoside and sorafenib on angiogenesis in vitro. $\mathbf{a}$ and $\mathbf{c}$, Matrigel tube-formation assay of HUVECs. Cells were treated with acteoside $(\mathrm{A} 01 ; 100$ or $500 \mu \mathrm{M})$ and sorafenib (sora; $10 \mu \mathrm{M})$ alone or in combination. Tube formation was then evaluated at $3 \mathrm{~h}$ and $8 \mathrm{~h}$ posttreatment. $\mathbf{b}$ and $\mathbf{d}$, Wound healing assay in HUVECs. The cell layer was scratched with a pipette tip. Cells were then treated with acteoside (A01; 100 or $500 \mu \mathrm{M}$ ) and sorafenib (sora; $10 \mu \mathrm{M}$ ) alone or in combination. Cell migration was visualized at the indicated time point $(0$ and $10 \mathrm{~h})$ under an inverted light microscope at a magnification of $\times 100$. Scale bar, $500 \mu \mathrm{m}$. Data are expressed as mean \pm SD from three independent experiments. ${ }^{*}, p<0.01$ vs the control group or otherwise as specified

only produced a tendency of prevention of wound healing with no statistical significance (Fig. 3a and d). For HLF cells, A01 at $500 \mu \mathrm{M}$ and sorafenib at $10 \mu \mathrm{M}$ inhibited wound healing. In particular, A01 $(500 \mu \mathrm{M})$ combined with sorafenib $(10 \mu \mathrm{M})$ produced a stronger inhibition of wound healing than sorafenib alone (Fig. 3b and e). For $\mathrm{JHH}$ cells, the wound healing was prevented by $\mathrm{A} 01(500 \mu \mathrm{M})$ and sorafenib $(10 \mu \mathrm{M})$. The combination of $\mathrm{A} 01(100 \mu \mathrm{M})$ and sorafenib $(10 \mu \mathrm{M})$ produced a stronger inhibition of wound healing than A01 $(100 \mu \mathrm{M})$ or sorafenib $(10 \mu \mathrm{M})$ alone. Moreover, A01 at $500 \mu \mathrm{M}$ combined with sorafenib $(10 \mu \mathrm{M})$ showed a stronger inhibition of wound healing than A01 $(500 \mu \mathrm{M})$ or sorafenib $(10 \mu \mathrm{M})$ alone (Fig. 3c and f).

\section{Effects of A01 alone or in combination with sorafenib on angiogenesis in vitro}

Angiogenesis is closely associated with tumor growth, progression and metastasis [16], and thus considered as one of the intervening targets for cancer treatment.
We first performed tube formation assay to analyze the potential angiogenesis in vitro. As shown in Fig. 4, treatment for $3 \mathrm{~h}$ with sorafenib alone $(10 \mu \mathrm{M})$ or the combination of A01 (100 and $500 \mu \mathrm{M})$ and sorafenib $(10 \mu \mathrm{M})$ started to show inhibitory effects on the formation of vessel-like structures, i.e. the elongation and alignment of the HUVECs (Fig. 4a and c). Following a treatment for $8 \mathrm{~h}$, A01 $(100$ and $500 \mu \mathrm{M})$, sorafenib $(10 \mu \mathrm{M})$ as well as the combination of A01 and sorafenib all inhibited significantly the formation of vessel-like structures, with stronger inhibition by the combination of $\mathrm{A} 01$ and sorafenib than A01 or sorafenib alone (Fig. 4a and c). In addition, the cell migration of HUVECs is a key step to form new vessels during angiogenesis and is thereby investigated. As shown in Fig. 4b and d, A01 $(500 \mu \mathrm{M})$, sorafenib $(10 \mu \mathrm{M})$ as well as the combination of A01 (100 and $500 \mu \mathrm{M})$ and sorafenib $(10 \mu \mathrm{M})$ all inhibited significantly cell migration of HUVECs. A01 $(500 \mu \mathrm{M})$ combined with sorafenib $(10 \mu \mathrm{M})$ produced stronger 


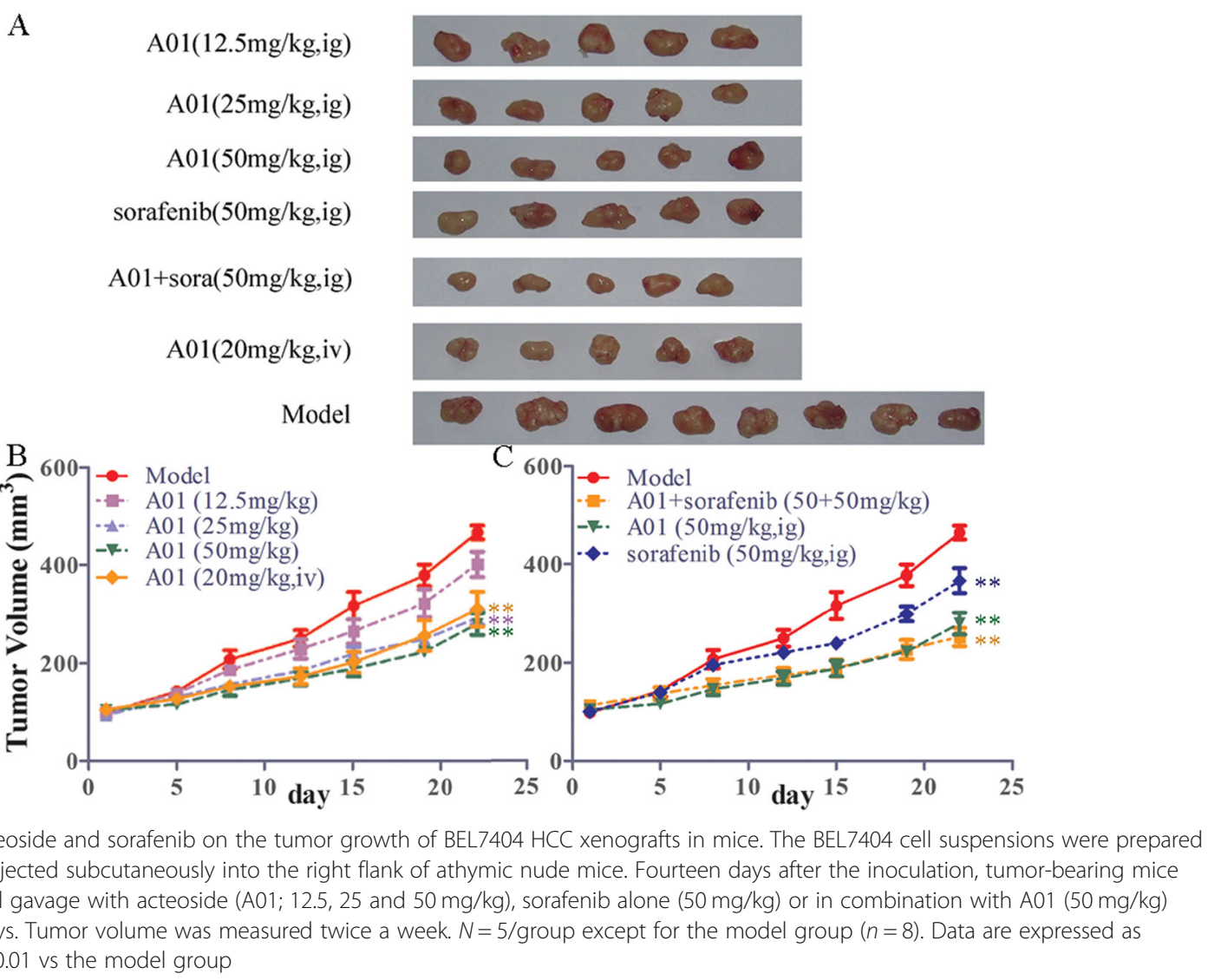

inhibition than A01 $(500 \mu \mathrm{M})$ or sorafenib $(10 \mu \mathrm{M})$ alone.

\section{Effects of A01 alone or in combination with sorafenib on the in vivo tumor growth of BEL7404 and JHH-7 HCC xenografts}

To further evaluate the effectiveness of A01 alone or combined with sorafenib on the in vivo tumor growth of HCC, we established a subcutaneous xenograft nude mouse model using BEL7404 or JHH-7 cells. As shown in Fig. 5, the tumor volume was greatly decreased following treatment with $\mathrm{A} 01$ ( 25 and $50 \mathrm{mg} / \mathrm{kg}$, via oral gavage; $20 \mathrm{mg} / \mathrm{kg}$, via tail vein; all $p<0.01$ vs model group) or sorafenib $(50 \mathrm{mg} / \mathrm{kg}$, via oral gavage; $p<0.01$ vs model group) alone (Fig. $5 \mathrm{a}$ and b). The combination of A01 $(50 \mathrm{mg} / \mathrm{kg})$ and sorafenib $(50 \mathrm{mg} / \mathrm{kg})$ showed a stronger inhibition of tumor growth when compared with sorafenib alone $(\mathrm{p}<0.01)$, but produced a similar effect as A01 alone (Fig. 5a and c). We next used the $\mathrm{JHH}-7$ xenograft nude mice model to further test the possible anti-tumor efficacies of A01. As shown in Fig. 6, treatment with A01 $(20 \mathrm{mg} / \mathrm{kg}$, iv) or sorafenib $(50 \mathrm{mg} /$ $\mathrm{kg}$, ig) produced a significant inhibition of tumor growth of JHH-7 xenograft ( $p<0.01$ vs model group), with greater inhibition when combined together (Fig. 6a and $\mathrm{b} ; \mathrm{p}<0.01$ vs A01 or sorafenib group alone).

\section{Possible modulation of kallikrein-related peptidase and p53 by acteoside}

The kallikrein-related peptidase (KLK) has been suggested as a cancer biomarker in the diagnosis and prognosis of various cancers, including hepatocellular carcinoma due to its dysregulated expression [17-19]. In this scenario, we detected gene expression of KLK1-15 in $\mathrm{HCC}$ JHH-7 cell line. As shown in Fig. 7, treatment with acteoside produced a significant inhibition of KLK1, 2, 4, 9 and 10 mRNA levels (Fig. 7a-e), with no significant changes of the rest of KLK1-15 (data not shown). In addition, we also detected the level of tumor suppressor protein p53 and revealed an increase by the treatment with acteoside (Fig. 7f).

\section{Discussion}

The management of advanced HCC has long been intractable due to the inability of diagnosis at earlier stages and the chemoresistance of the tumor $[5,6]$. Sorafenib, the multikinase inhibitor reported to inhibit cell proliferation and angiogenesis, together with another oral multikinase inhibitor lenvatinib has become the standard 


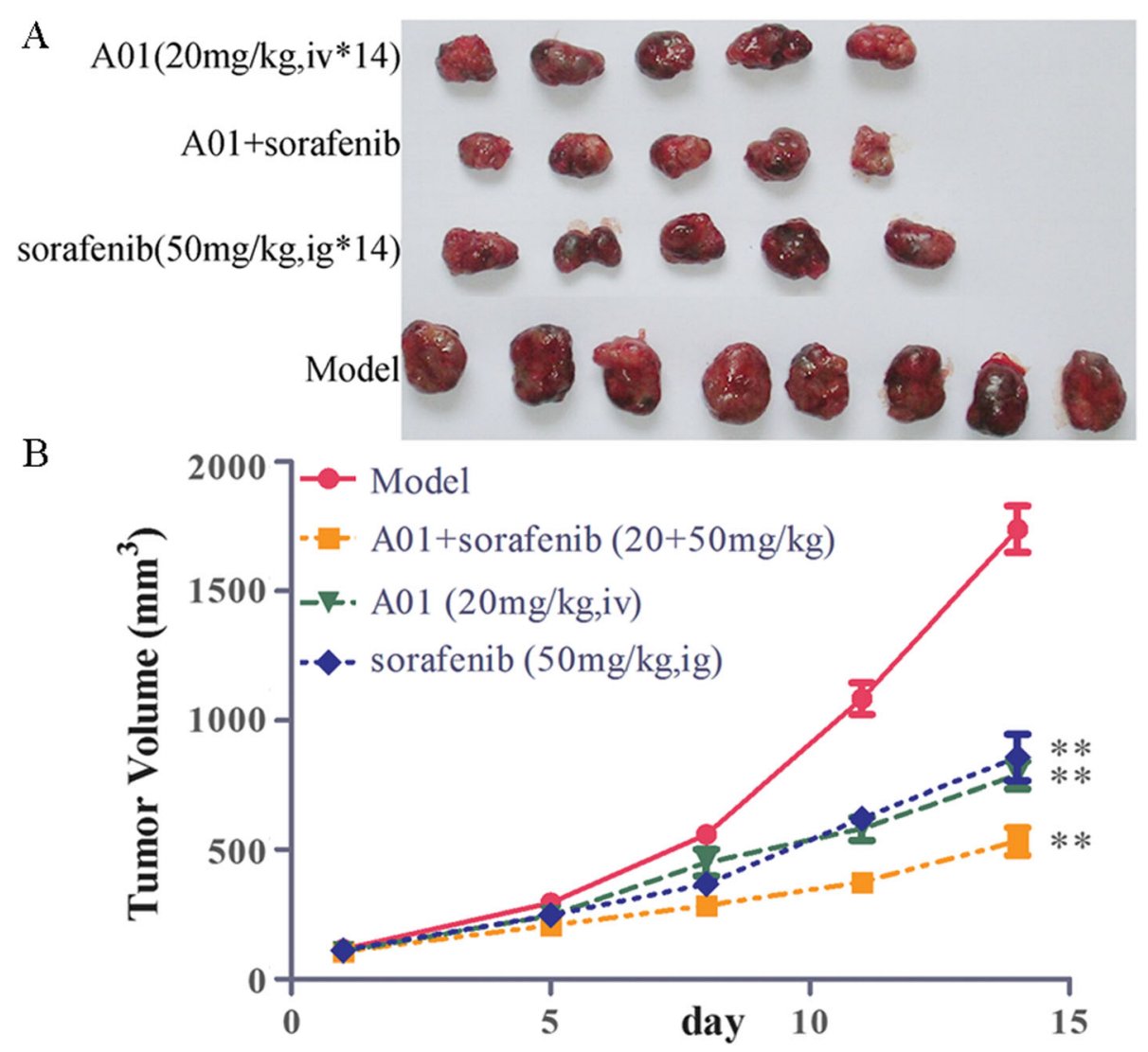

Fig. 6 Effects of acteoside and sorafenib on the tumor growth of $\mathrm{JHH}-7 \mathrm{HCC}$ xenografts in mice. The $\mathrm{JHH}-7$ cell suspensions were prepared $(3 \times$ $10^{6}$ cells) and injected subcutaneously into the right flank of athymic nude mice. Fourteen days after the inoculation, tumor-bearing mice were treated with acteoside (A01; $20 \mathrm{mg} / \mathrm{kg}$; iv), sorafenib alone (50 mg/kg;ig) or in combination with A01 (20 mg/kg; iv) once daily for 14 days. Tumor volume was measured twice a week. Data are expressed as mean \pm SEM. $N=5 /$ group except for the model group $(n=8)$. ${ }^{* *}, p<0.01$ vs the model group

treatment of advanced $\mathrm{HCC}[3,5,20,21]$. However, the overall survival rates are modest in light of the low response rates and unsuitability in the clinical settings [3, $22]$. A recent study showed that atezolizumab plus bevacizumab produced better clinical outcomes than sorafenib in patients with unresectable HCC, making this combination a possible new first-line treatment option for advanced HCC [7]. In this context, we have identified that the phenylethanoid glycoside, acteoside inhibited cell proliferation, colony formation and migration in the three human HCC cell lines BEL7404, HLF and JHH-7 as well as prohibited angiogenesis of HUVECs. The combination of acteoside and sorafenib produced stronger inhibition of cell colony formation and migration of the HCC cells as well as of angiogenesis of HUVECs. Acteoside presented the antitumor efficacy in BEL7404 or JHH-7 xenograft nude mice model, with an enhancement when combined with sorafenib in inhibiting the growth of JHH-7 xenograft. Further analyses revealed an increase in p53 as well as a decrease of some KLK genes. Accordingly, the possible use of acteoside as adjuncts in the treatment of advanced HCC in the clinic should be considered.

Mounting evidence has shown the antitumor effects of acteoside in various tumor cells such as B16 melanoma cells, glioblastoma cells, colorectal cancer cells, oral squamous cell carcinoma cells, prostate cancer cells and human breast adenocarcinoma cells [11-13, 23-25] or in animals bearing tumors [12]. Despite that, few studies have focused on the effects of acteoside on HCC in vitro or in vivo except one study using diethylnitrosamine as the carcinogen to induce hepatocarcinogenesis in rats and revealing the chemoprevention by acteoside [26]. In the current study, we showed the inhibition by acteoside of cell proliferation, colony formation and migration in HCC cell lines as well as tumor growth in mice bearing HCC cell line xenografts, thereby directly demonstrating the antitumor effects of acteoside in HCC. Furthermore, the combination of acteoside and sorafenib produced even stronger antitumor effects. Combined with the evidence that acteoside is protective against liver injuries [27-29] with no toxic effects in animals and no 

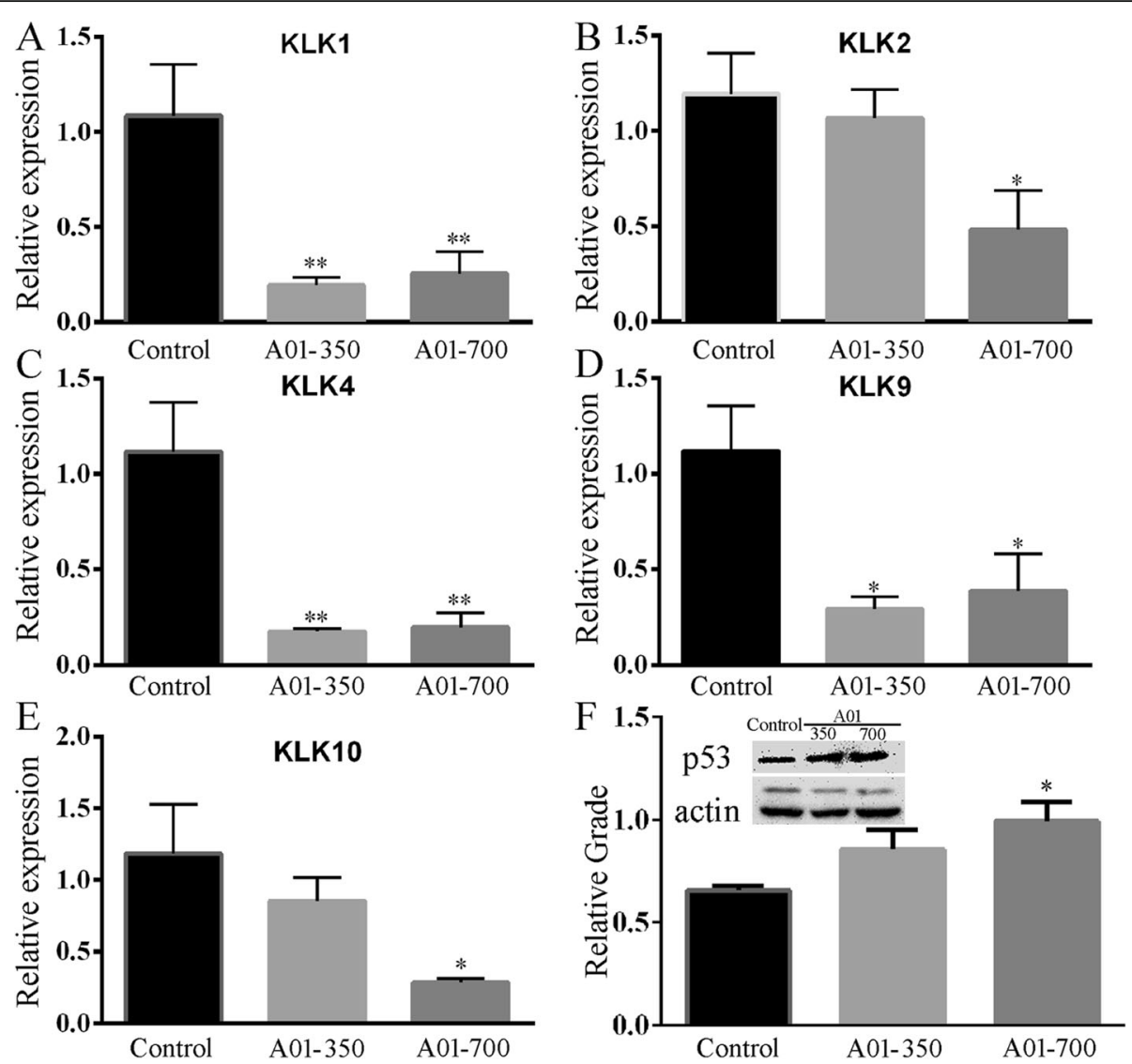

Fig. 7 Changes of kallikrein-related peptidase (KLK) mRNA levels and tumor suppressor protein p53 levels following treatment of JHH-7 cells with acteoside. a-e, The down-regulation of KLK1, 2, 4, 9 and 10 mRNA levels was observed by acteoside (A01) at 350 or $700 \mu$ M (A01-350 or A01700). $\mathbf{f}$, Changes of p53 by western blot analyses. Treatment with acteoside (A01) increased p53 levels. Data are expressed as mean \pm SEM ( $n=4 /$ group). ${ }^{*}, p<0.05$ vs the control group; ${ }^{* *}, p<0.01$ vs the control group

mutagenicity [30], it seems to be feasible for the future application of the combination therapy of acteoside and sorafenib in patients with advanced HCC in the clinic.

The human kallikrein family comprises 15 homologous, single-chain, secreted trypsin- or chymotrypsinlike serine proteases (KLK1-15) and has been implicated in regulation of tumor growth, neoplastic progression, angiogenesis and metastasis $[18,31]$. In particular, the KLKs have been suggested as a cancer biomarker in the diagnosis and prognosis of various cancers, including hepatocellular carcinoma due to its dysregulated expression [17-19]. For example, KLK1 is proposed as the biomarker of gastric cancer due to the elevation of KLK1 levels in gastric neoplasm and the prevention of tumor growth in gastric cancer by inhibition of KLK1 activity with kallikrein-binding protein (KBP) [32]. In this scenario, we observed a significant inhibition of KLK mRNA levels by acteoside (KLK1, 2, 4, 9 and 10). Application of KBP, which specifically binds to tissue kallikrein and inhibits kallikrein activity, was reported to suppress growth of HCC in mice possibly via its anti- angiogenic activity [33], suggesting the possible involvement of KLKs in the progression of HCC. In addition, the tumor suppressor protein p53 is able to induce senescence, apoptosis as well as cell cycle arrest. Increased p53 expression confers enhanced chemosensitivity in cancer cells [34]. In this regard, our western results showed an increase in p53 levels following treatment with acteoside. Taken together, it is reasonable to infer that acteoside exerts the antitumor effects on HCC possibly through its up-regulation of p53 as well as inhibition of KLK and angiogenesis.

It should be noted that the direct molecular target to which acteoside could directly bind is still unclear. Our preliminary data using molecular docking revealed a direct binding of acteoside with kallikrein (data not shown). Further experiments would be necessary to clarify this presumption. In addition, as for the doses of acteoside used for cell assay in the study 10-50 times higher than that of sorafenib $(10 \mu \mathrm{M})$, firstly we chose those doses of acteoside in accordance with the dose-response relationship in the MTT assay. Second, the doses we used (100, 
$500 \mu \mathrm{M})$ were comparable to previous studies [35], in which acteoside $(100 \mu \mathrm{M})$ inhibited cell proliferation of colorectal cancer cell. Last, despite the higher dose in the cell assay, acteoside produced a pronounced inhibition of tumor growth in the HCC xenograft nude mice model in our study ( 25 and $50 \mathrm{mg} / \mathrm{kg}$ ), effects being similar to sorafenib $(50 \mathrm{mg} / \mathrm{kg})$. For sorafenib, it was used in our study at the dose of $10 \mu \mathrm{M}$ at the cellular level. This dose is comparable to previous studies in which sorafenib was found to inhibit the cell viability with an $\mathrm{IC}_{50}$ of $4.0-6.5 \mu \mathrm{M}$ in the HCC cell lines of PLC/PRF/5 and HepG2 cells. In contrast, the dose of sorafenib used to suppress the growth of HCC xenografts in SCID female mice was $30 \mathrm{mg} / \mathrm{kg}$ (p.o. by gavage) [36]. In the clinic, the recommended dosage of sorafenib for patient is $400 \mathrm{mg}$ per time $(2 * 0.2 \mathrm{~g})$, twice a day $(800 \mathrm{mg}$ per day in total). This dosage for sorafenib used in the clinic is in contrast to that used in cell assay (IC50 value in $\mu \mathrm{M}$ level), possibly due to its poor absorbability under in vivo conditions. For acteoside, based on its dosage in mice $(50 \mathrm{mg} / \mathrm{kg}$, i.g.), its equivalent dose for human (60 $\mathrm{kg}$ bw) is about $250 \mathrm{mg}$. This dosage is comparable to that of sorafenib used in the clinic and should be acceptable for the patients.

\section{Conclusions}

In conclusion, acteoside is capable of exerting an antitumor effect in HCC cell lines and in nude mice bearing HCC cell line xenografts, effects possibly via increasing p53 levels as well as prohibiting KLK and angiogenesis. Acteoside could be useful as an adjunct in the treatment of advanced HCC in the clinic.

\section{Supplementary information}

Supplementary information accompanies this paper at https://doi.org/10. 1186/s12885-020-07447-3.

Additional file 1: Supplemental Figure 1. Full image of western blotting bands for p53 and its internal control actin shown in Fig. $7 f$. Membrane was pre-cut according to the molecular weight of p53 and Bax. After p53 (or Bax) staining, the membrane was stripped with stripping buffer and reprobed with the actin antibody (or $\mathrm{BCl}-2$ ). Note that the remanant obscure p53 band was seen right above the actin band.

Additional file 2.

\section{Abbreviations}

A01: acteoside; HCC: Hepatocellular carcinoma; HUVEC: Human umbilical vein endothelial cell; KLK: kallikrein-related peptidase; MTT: 3-(4,5Dimethylthiazol-2-yl)-2,5-diphenyltetrazolium bromide; RIPA: radioimmunoprecipitation assay buffer

\section{Acknowledgements}

Not applicable.

\section{Authors' contributions}

DM and JW performed the cell and animal experiments and analyzed the data. LL and MC performed the western and PCR experiments. ZW designed the projects and drafted the manuscript. All authors have read and approved the final manuscript.

\section{Funding}

This work was supported by a grant from the Shanghai Science and Technology Committee (No. 18DZ2290900). This grant had no role in the design of the study and collection, analysis and interpretation of data and in writing the manuscript.

\section{Availability of data and materials}

All analyzed data are included in this published article. The original data are available upon request to the corresponding author.

\section{Ethics approval and consent to participate}

Animal experiments were approved by the Institutional Animal Care and Use Committee of Shanghai Institute of Pharmaceutical Industry and performed in accordance with the guidelines of the International Association for the Study of Pain concerning the use of laboratory animals. This study did not involve any human participants, human data or human tissue. The HCC cell lines used in this study require no ethics approval.

\section{Consent for publication}

Not applicable.

\section{Competing interests}

The authors declare that they have no competing interests.

\section{Author details}

${ }^{1}$ Department of General Surgery, Ruijin Hospital, Shanghai Jiaotong University School of Medicine, Shanghai 200025, China. ${ }^{2}$ China State Key Laboratory of New Drug \& Pharmaceutical Process, Center for Pharmacological Evaluation and Research, Shanghai Institute of Pharmaceutical Industry, 1111 Rd. Zhongshanbeiyi, Hongkou, Shanghai 200437, China.

Received: 4 March 2020 Accepted: 21 September 2020

Published online: 29 September 2020

References

1. Bray F, Ferlay J, Soerjomataram I, Siegel RL, Torre LA, Jemal A. Global cancer statistics 2018: GLOBOCAN estimates of incidence and mortality worldwide for 36 cancers in 185 countries. CA Cancer J Clin. 2018;68(6):394-424..

2. Llovet JM, Zucman-Rossi J, Pikarsky E, Sangro B, Schwartz M, Sherman M, Gores G. Hepatocellular carcinoma. Nat Rev Dis Primers. 2016;2:16018.

3. Sim HW, Knox J. Hepatocellular carcinoma in the era of immunotherapy. Curr Probl Cancer. 2018;42(1):40-8.

4. Jiang Y, Han QJ, Zhang J. Hepatocellular carcinoma: mechanisms of progression and immunotherapy. World J Gastroenterol. 2019;25(25):315167.

5. Forner A, Da Fonseca LG, Diaz-Gonzalez A, Sanduzzi-Zamparelli M, Reig M, Bruix J. Controversies in the management of hepatocellular carcinoma. JHEP Rep. 2019;1(1):17-29.

6. Hartke J, Johnson M, Ghabril M. The diagnosis and treatment of hepatocellular carcinoma. Semin Diagn Pathol. 2017;34(2):153-9.

7. Finn RS, Qin S, Ikeda M, Galle PR, Ducreux M, Kim TY, Kudo M, Breder V, Merle $\mathrm{P}$, Kaseb AO, et al. Atezolizumab plus Bevacizumab in Unresectable Hepatocellular Carcinoma. N Engl J Med. 2020;382(20):1894-905.

8. He ZD, Ueda S, Akaji M, Fujita T, Inoue K, Yang CR. Monoterpenoid and phenylethanoid glycosides from Ligustrum pedunculare. Phytochemistry. 1994;36(3):709-16.

9. Li H, Chou GX, Wang ZT, Hu ZB. HPLC determination of acteoside in Radix Rehmanniae. Zhongguo Zhong Yao Za Zhi. 2006;31(10):822-4.

10. Wong IY, He ZD, Huang Y, Chen ZY. Antioxidative activities of phenylethanoid glycosides from Ligustrum purpurascens. J Agric Food Chem. 2001;49(6):3113-9.

11. Mulani SK, Guh JH, Mong KK. A general synthetic strategy and the antiproliferation properties on prostate cancer cell lines for natural phenylethanoid glycosides. Org Biomol Chem. 2014;12(18):2926-37.

12. Cheimonidi C, Samara P, Polychronopoulos P, Tsakiri EN, Nikou T, Myrianthopoulos V, Sakellaropoulos T, Zoumpourlis V, Mikros E, Papassideri I, et al. Selective cytotoxicity of the herbal substance acteoside against tumor cells and its mechanistic insights. Redox Biol. 2018;16:169-78. 
13. Attia YM, El-Kersh DM, Wagdy HA, Elmazar MM. Verbascoside: identification, quantification, and potential sensitization of colorectal Cancer cells to 5-FU by targeting PI3K/KT pathway. Sci Rep. 2018;8(1):16939.

14. Liu S, Zhao Z, Huo Z, Xu Z, Zhong Y, Wang X, Yang Y, Wang Z. Osmanthus fragrans flower aqueous extract and its enriched acteoside inhibit melanogenesis and ultraviolet-induced pigmentation. Nat Prod Commun. 2018;13(5):575-80

15. Wang J, Ma S, Chen X, Zhang S, Wang Z, Mei Q. The novel PI3K inhibitor S1 synergizes with sorafenib in non-small cell lung cancer cells involving the Akt-S6 signaling. Investig New Drugs. 2019;37(5):828-36.

16. Hanahan D, Weinberg RA. Hallmarks of cancer: the next generation. Cell. 2011;144(5):646-74.

17. Emami N, Diamandis EP. Utility of kallikrein-related peptidases (KLKS) as cancer biomarkers. Clin Chem. 2008:54(10):1600-7.

18. Tailor PD, Kodeboyina SK, Bai S, Patel N, Sharma S, Ratnani A, Copland JA, She JX, Sharma A. Diagnostic and prognostic biomarker potential of kallikrein family genes in different cancer types. Oncotarget. 2018;9(25): $17876-88$

19. Kontos CK, Mavridis K, Talieri M, Scorilas A. Kallikrein-related peptidases (KLKs) in gastrointestinal cancer: mechanistic and clinical aspects. Thromb Haemost. 2013;110(3):450-7.

20. Cheng AL, Kang YK, Chen Z, Tsao CJ, Qin S, Kim JS, Luo R, Feng J, Ye S, Yang TS, et al. Efficacy and safety of sorafenib in patients in the Asia-Pacific region with advanced hepatocellular carcinoma: a phase III randomised, double-blind, placebo-controlled trial. Lancet Oncol. 2009;10(1):25-34.

21. Llovet JM, Ricci S, Mazzaferro V, Hilgard P, Gane E, Blanc JF, de Oliveira AC, Santoro A, Raoul JL, Forner A, et al. Sorafenib in advanced hepatocellular carcinoma. N Engl J Med. 2008;359(4):378-90.

22. Song MJ. Hepatic artery infusion chemotherapy for advanced hepatocellular carcinoma. World J Gastroenterol. 2015;21(13):3843-9.

23. Liao YF, Rao YK, Tzeng YM. Aqueous extract of Anisomeles indica and its purified compound exerts anti-metastatic activity through inhibition of NFkappaB/AP-1-dependent MMP-9 activation in human breast cancer MCF-7 cells. Food Chem Toxicol. 2012;50(8):2930-6.

24. Zhang Y, Yuan Y, Wu H, Xie Z, Wu Y, Song X, Wang J, Shu W, Xu J, Liu B, et al. Effect of verbascoside on apoptosis and metastasis in human oral squamous cell carcinoma. Int J Cancer. 2018;143(4):980-91.

25. Hwang TW, Kim DH, Kim DB, Jang TW, Kim GH, Moon M, Yoon KA, Choi DE, Park JH, Kim JJ. Synergistic anticancer effect of acteoside and temozolomide-based glioblastoma chemotherapy. Int J Mol Med. 2019; 43(3):1478-86

26. Peerzada KJ, Faridi AH, Sharma L, Bhardwaj SC, Satti NK, Shashi B, Tasduq SA. Acteoside-mediates chemoprevention of experimental liver carcinogenesis through STAT-3 regulated oxidative stress and apoptosis. Environ Toxicol. 2016;31(7):782-98.

27. Cui Q, Pan Y, Zhang W, Zhang Y, Ren S, Wang D, Wang Z, Liu X, Xiao W. Metabolites of dietary Acteoside: profiles, isolation, identification, and Hepatoprotective capacities. J Agric Food Chem. 2018;66(11):2660-8.

28. Xiong Q, Hase K, Tezuka Y, Namba T, Kadota S. Acteoside inhibits apoptosis in D-galactosamine and lipopolysaccharide-induced liver injury. Life Sci. 1999;65(4):421-30.

29. Zhao J, Liu T, Ma L, Yan M, Zhao Y, Gu Z, Huang Y. Protective effect of acteoside on immunological liver injury induced by Bacillus CalmetteGuerin plus lipopolysaccharide. Planta Med. 2009;75(14):1463-9.

30. Lu B, Li M, Zhou F, Huang W, Jiang Y, Mao S, Zhao Y, Lou T. The Osmanthus fragrans flower phenylethanoid glycoside-rich extract: acute and subchronic toxicity studies. J Ethnopharmacol. 2016;187:205-12.

31. Diamandis EP, Yousef GM. Human tissue kallikreins: a family of new cancer biomarkers. Clin Chem. 2002;48(8):1198-205.

32. Sawant S, Snyman C, Bhoola K. Comparison of tissue kallikrein and kinin receptor expression in gastric ulcers and neoplasms. Int Immunopharmacol. 2001;1(12):2063-80.

33. Lu L, Yang Z, Zhu B, Fang S, Yang X, Cai W, Li C, Ma JX, Gao G. Kallikreinbinding protein suppresses growth of hepatocellular carcinoma by antiangiogenic activity. Cancer Lett. 2007;257(1):97-106.

34. Guntur VP, Waldrep JC, Guo JJ, Selting K, Dhand R. Increasing p53 protein sensitizes non-small cell lung cancer to paclitaxel and cisplatin in vitro. Anticancer Res. 2010;30(9):3557-64.

35. Zhou L, Feng Y, Jin Y, Liu X, Sui H, Chai N, Chen X, Liu N, Ji Q, Wang Y, Li Q. Verbascoside promotes apoptosis by regulating HIPK2-p53 signaling in human colorectal cancer. BMC Cancer. 2014;14:747.
36. Liu L, Cao Y, Chen C, Zhang X, McNabola A, Wilkie D, Wilhelm S, Lynch M, Carter C. Sorafenib blocks the RAF/MEK/ERK pathway, inhibits tumor angiogenesis, and induces tumor cell apoptosis in hepatocellular carcinoma model PLC/PRF/5. Cancer Res. 2006;66:11851-8.

\section{Publisher's Note}

Springer Nature remains neutral with regard to jurisdictional claims in published maps and institutional affiliations.
Ready to submit your research? Choose BMC and benefit from:

- fast, convenient online submission

- thorough peer review by experienced researchers in your field

- rapid publication on acceptance

- support for research data, including large and complex data types

- gold Open Access which fosters wider collaboration and increased citations

- maximum visibility for your research: over $100 \mathrm{M}$ website views per year

At BMC, research is always in progress.

Learn more biomedcentral.com/submissions 